\title{
Assessing mental well-being in a Sinhala speaking Sri Lankan population: validation of the WHO-5 well-being index
}

\author{
B. P. R. Perera ${ }^{1 *} \mathbb{D}$, R. Jayasuriya ${ }^{2}$, A. Caldera ${ }^{1}$ and A. R. Wickremasinghe ${ }^{1}$
}

\begin{abstract}
Purpose: The WHO-5 well-being index is a widely used, short rating scale that measures subjective well-being. We translated the WHO-5 index into Sinhala and tested its psychometric properties including measurement invariance among diverse groups in a community sample in Sri Lanka.

Methods: The sample of 267 persons aged between 16 and 75 years was recruited from a semi-urban area. 219 completed a paper-based questionnaire and 48 responded to an online survey. Construct validity was tested for factorial validity (Confirmatory Factor Analysis -CFA), convergent validity and known group validity. Composite reliability for congeneric measures and test-retest reliability were also tested. Multi-group CFA (MG-CFA) was used to test measurement invariance.
\end{abstract}

Results: The translated Sinhala version demonstrated good content and face validity. Internal consistency reliability of the five items had a Cronbach's alpha of 0.85 and test-retest reliability over 2 weeks was satisfactory (Pearson $r=$ $0.72, p<0.001$, ICC $=0.82)$. Confirmatory factor analysis supported factorial validity with a $X_{5}^{2}=4.99(p=0.28)$, a RMSEA of 0.03 ( $90 \%$ C.I. $=0.00-0.10$ ), a SRMR of 0.02, a TLI of 0.99 and a CFI of 0.99; factor loadings were between 0.55 and 0.89 . Measurement invariance was acceptable for configural, metric and scalar invariance for gender. WHO-5 scores were significantly negatively correlated with the Patient Health Questionnaire (PHQ-9) (Pearson's $r=$ $-0.45, p<0.001)$ scores and the Kessler Psychological Distress Scale (K10) scores (Pearson's $r=-0.56, p<0.001$ ).

Conclusion: The Sinhala translation of WHO-5 well-being index has shown acceptable psychometric properties and can be used for assessing mental well-being in the community in Sri Lanka. Further testing of the measure with larger and diverse (including different ethnic/cultural) groups are indicated to test measurement invariance of the measure.

Keywords: WHO-5 Sinhala version, Validation, Well-being, Sri Lanka

\footnotetext{
* Correspondence: bprperera@gmail.com

'Department of Public Health, Faculty of Medicine, University of Kelaniya,

P.O. Box 6, Thalagolla Road, Ragama 11010, Sri Lanka

Full list of author information is available at the end of the article
}

(c) The Author(s). 2020 Open Access This article is licensed under a Creative Commons Attribution 4.0 International License, which permits use, sharing, adaptation, distribution and reproduction in any medium or format, as long as you give appropriate credit to the original author(s) and the source, provide a link to the Creative Commons licence, and indicate if changes were made. The images or other third party material in this article are included in the article's Creative Commons licence, unless indicated otherwise in a credit line to the material. If material is not included in the article's Creative Commons licence and your intended use is not permitted by statutory regulation or exceeds the permitted use, you will need to obtain permission directly from the copyright holder. To view a copy of this licence, visit http://creativecommons.org/licenses/by/4.0/ The Creative Commons Public Domain Dedication waiver (http://creativecommons.org/publicdomain/zero/1.0/) applies to the data made available in this article, unless otherwise stated in a credit line to the data. 


\section{Introduction}

The World Health Organization-5 (WHO-5) well-being index was developed in response to the need of an instrument to measure subjective well-being which reflects a single dimension with high clinical face validity [1]. WHO-5 was derived from WHO-10 which has its origin from a 28-item rating scale that was used in a multi-centre study in eight European countries [2]. The 10 items of the WHO-10 were selected from the 28-item scale using item response theory (IRT) analysis [2]. WHO-10 includes items phrased positively reflecting well-being and phrased negatively to reflect distress [2]. As the WHO definition of good health considers positive well-being reflecting mental health, the WHO-5 comprises only the positively phrased items of $\mathrm{WHO}-10$.

A systematic review of its use found that it has been translated into more than 30 languages and has been used in research studies globally $[1,3]$. The validity of the WHO-5 has been tested in different countries and settings, but predominantly in high income settings in the west and Japan [4-14] as a robust outcome measure of well-being $[4,6,8,9,15,16]$. However, there are only a very few validations in Low- and Middle-Income Countries (LMIC), and specifically in Asia [15, 17]. The aim of this study was to assess the psychometric properties of a translation of the WHO-5 well-being index into Sinhala in Sri Lanka, a South Asian country.

In our review of the corpus of validation studies including the systematic review [1], only two studies have been conducted to test measurement invariance to assess whether the WHO-5 is being understood and interpreted in a similar manner by diverse groups such as by gender, age group, education levels and different culture/language groups in each setting $[18,19]$. Therefore, the second aim of the study was to test measurement invariance of the WHO-5 among diverse groups using the Sinhala language.

\section{Methods}

\section{Participants and recruitment}

A community sample was recruited by contacting households in a sub-division of a district demarcated for population health services, called a Medical Officer of Health $(\mathrm{MOH})$ area, in a semi-urban setting in the western province of Sri Lanka. Staff of the MOH obtained consent from Sinhala speaking participants 16 to 75 years of either sex for research assistants to visit on pre-arranged days and administer the questionnaire at their homes. In addition, an online version of the questionnaire was posted using Google Forms and accessible to participants who were contacted via word of mouth using a snowballing technique.

\section{Scales used}

\section{WHO-5 well-being index}

The five statements in the WHO-5 well-being index are: 1) 'I have felt cheerful and in good spirits', 2) 'I have felt calm and relaxed', 3) 'I have felt active and vigorous', 4) 'I woke up feeling fresh and rested' and 5) 'My daily life has been filled with things that interest me'. The degree to which these feelings were present in the last 14 days were scored on a 6 -point Likert-type scale ranging from 0 ("at no time") to 5 ("all of the time"). The item scores were summated to obtain an individual score ranging from 0 to 25, with higher scores indicating higher levels of well-being. As scales measuring health-related quality of life are conventionally translated to a percentage score, the summated score was transformed to a $0-100$ score by multiplying the summated score by 4 [3].

\section{Translation and content validation of the WHO-5 well-being index to Sinhala}

The scale was translated into Sinhala language following an accepted process [20]. The original scale was translated into Sinhala language by two independent bilingual translators. The translation was then synthesized into one version by an investigator. This synthesized version was then back translated into English by two independent bilingual translators who were not aware of the original scale. Discrepancies were resolved to obtain the final version of the translated scale. The process was done for several iterations until the back translation to English was similar to the original English version of the questionnaire. An expert committee consisting of two experts who are familiar with the construct of interest, a methodologist, and both the forward and backward translators was convened. Content and face validity of the Sinhala translation was assessed by the expert panel [21].

The WHO-5 instrument was subjected to a cognitive test with 10 respondents to assess clarity and appropriateness of the wording [22]. The respondents were asked to complete the questionnaire and then were asked to describe what they understood by each item and why they selected a particular response for that item to assess whether it matched with the meaning of the original item.

\section{Patient health questionnaire (PHQ-9)}

The PHQ-9 depression module is a nine-item scale derived from the full PHQ. The severity of the symptoms is rated on a scale from 0 to 3 which corresponds to "not at all" to "nearly every day", respectively. The PHQ9 score can range from 0 to 27 , higher values indicating increasing severity [23]. The translated questionnaire was tested among a Sinhala speaking Sri Lankan population and found to have good reliability with a Cronbach's alpha of 0.90 and convergent validity [22].

\section{Kessler psychological distress scale (K10)}

The Kessler psychological distress scale is a mental health screening tool, used in population surveys, that is based on a 10-item five-point Likert type scale ranging 
from 0 to 4; it assesses the level of anxiety and depressive symptoms a person may have experienced in the past 4 weeks [24]. The translated questionnaire has been tested for its criterion validity using SCID in a Sinhala speaking population in Sri Lanka [24].

\section{Sample size}

There are several factors that affect the sample size requirement for structural equation model (SEM) testing which include the complexity of the model, number of parameters to estimate and reliability of measures [25]. Using one such heuristic, the N:q rule, given that there are 15 parameters to estimate in a congeneric model for Confirmatory Factor Analysis [26], a sample size of 150 (for a 10:1 ratio) and 300 (for a 20:1 ratio) can be considered minimal and good, respectively [25].

\section{Psychometric analysis \\ Reliability}

Cronbach's alpha was used to assess internal consistency reliability; an $\alpha>0.7$ and item-total correlation coefficients of $>0.5$ were considered to indicate satisfactory reliability. Composite reliability for congeneric measures were tested using confirmatory factor analysis (CFA) for all standard factor loadings of 0.6 or above [25].

The test-retest reliability of the scale within a span of 2 weeks was assessed in a sample of 38 participants using the Pearson's product-moment correlation coefficient and Intraclass Correlation Coefficient (ICC) based on the absolute agreement in a two-way mixed method model. Reliability was classified as poor $(\mathrm{ICC}<0.5)$, moderate (ICC $0.5-0.75$ ), good (ICC $0.75-0.9)$ or excellent $(\mathrm{ICC}>0.90)$ [27].

\section{Convergent and discriminant validity}

Convergent validity was tested with the validated Sinhala versions of PHQ-9 and K10 using the Pearson correlation coefficient. We hypothesized a negative correlation between WHO-5 and K10 and PHQ-9. A correlation of $<-0.5$ was considered to indicate satisfactory convergent validity [26, 28].

Known-group validity was used to assess discriminant validity. We hypothesised that there would be no difference by gender, ethnicity and religion. We expected to find a higher mean well-being score among older persons and those in higher education categories [29]. Those who scored higher in PHQ-9 and/or K10 indicating presence of depressive symptoms and/or anxiety were expected to have low scores in WHO-5.

\section{Construct validity}

CFA was used to test the factorial validity of the single factor congeneric model. As the response options were based on a six-item Likert scale, which had ordinal properties, best practice recommendations were followed to analyse the data using the mean and variance adjusted weighted least square (WLSMV) estimator which is also robust to non-normality of the data [30]. The CFA model testing procedures of model specification, identification, and estimation were followed to test model fit [25]. As the $\chi 2$ is known to overestimate minor model misspecifications, CMIN/DF $\left(\frac{\chi^{2}}{d f}\right)$ was used to assess model fit and ratios not exceeding three was considered an acceptable fit [31]. Four other approximate fit indices were considered: RMSEA $<0.050$ and $<0.080$ for close and reasonable fit, respectively: Comparative fit index (CFI) and Tucker-Lewis Index (TLI) of $>0.900$ and $>0.950$ were considered for acceptable and excellent fit, respectively [32]; Standard Root Mean Square Residual (SRMR) of $<0.05$ was also considered because this index is independent of the estimator used [33]. Since we used the DWLS estimator for our analysis, SRMR has been recommended as the main index to test model fit [34-37].

\section{Measurement invariance testing}

Testing measurement invariance can be considered under the wider concept of bias in construct validity which has been defined as "the extent to which a test measures different constructs for different groups" [38]. Bias is said to be present if a measure systematically overestimates or underestimates scores on a variable for members of a particular group [38]. Bias can manifest itself in many ways either at the item level (DIF) or at the scale level (differential test functioning, DTF) [39].

While there are many methods to test MI; Multi-Group CFA (MG-CFA) is a widely accepted approach, $[40,41]$ and is widely available in different statistical programmes (e.g., Mplus, R, EQS, etc.), and it can be conducted with ordinal data. In the context of ordinal/categorical item data, MG-CFA has been shown to be more sensitive than item response theory (IRT) in identifying items with DIF with a lower rate of false positives [42].

Invariance testing using MG-CFA involves examining the fit of a series of increasingly restrictive models $[25,39,43]$. The researcher begins by testing a baseline model with the groups and, if fit is established, proceeds by imposing increasingly restrictive equality constraints (see Kline 2016 for details). If model fit does not meaningfully change when equality constraints are included, then the measure is said to be equivalent/invariant [39].

Measurement invariance was assessed based on sex (male/female), age (above 40/below40), occupational status (working/not working) and method of data collection (paper-based/online).

\section{Data analysis}

Descriptive statistics are reported as frequencies and percentages or as means $( \pm S D)$. Differences of means 
between groups were tested using independent sample ttests or analysis of variance (ANOVA) and Student Neuman Keuls test for post-hoc comparisons. Statistical analysis was performed using IBM SPSS software version 22, CFA using lavaan 0.6-7.1565 and semPlot [44] packages in R software. Measurement invariance testing was conducted using Mplus 7.2.

\section{Ethics considerations}

Ethics approval was obtained from the Ethics Review Committee of the Faculty of Medicine, University of Kelaniya, Sri Lanka (Ref.No.P/128/06/2019). Informed consent was obtained from the participants in writing prior to responding to the questionnaire and the scales.

\section{Results}

\section{Sample characteristics}

Data were collected from a community sample and an online sample. In the community sample, 221 paperbased questionnaires were distributed, of which, 197 were returned (response rate 89\%). Eleven questionnaires were incomplete and were not used in the analysis. Seventy persons completed the online version of the questionnaire. In the final sample of 267 participants, the mean age was 34.1 years (SD 13.5 years; range 17 to 73 years), $72 \%$ were females and $96 \%$ were Sinhalese (4\% were Tamils and Muslims who were conversant in Sinhala). The majority were Buddhists (71\%), $42 \%$ of the sample had received an education up to grade $13,58 \%$ had a pursued higher education, $45 \%$ were employed, $23 \%$ were unemployed and $32 \%$ were students (Additional file 1).

\section{Psychological well-being of the study participants}

The mean $( \pm$ SD) score of the WHO-5 index was $56( \pm$ 23.9). The mean $( \pm \mathrm{SD})$ of the PHQ-9 score was $6.0( \pm$ 4.9) with 58 persons (22\%) having a PHQ-9 score $\geq 10$ indicating having depressive symptoms. The mean $( \pm \mathrm{SD})$ score of K10 was $10.1 \pm 7.5$, ranging from 0 to 40: using a cut-off value of 16,59 (22\%) individuals had psychological distress.

\section{Psychometric properties of Sinhala version of WHO-5 Reliability}

The Cronbach's alpha for the Sinhala version of the WHO-5 index for the whole group was 0.854; and itemtotal correlations were above 0.5 (range 0.61 to 0.75 ). Composite reliability for congeneric measures as tested using CFA showed that all standard factor loadings were 0.5 or above, ranging from 0.5 to 0.88 (Table 1 ).

The Pearson correlation coefficient and the ICC used to assess test-retest reliability over 2 weeks were 0.72 $(p<0.001)$ and $0.82(0.666-0.911)(p<0.001)$, respectively, indicating high test-retest reliability over 2 weeks (Table 2).

\section{Convergent and discriminant validity}

Overall, there was a significant inverse relationship between WHO-5 and PHQ-9 scores for the full sample (Pearson's $r=(-0.45), p<0.001)$ and for both the paper-based $(r=(-$ $0.46), p<0.001)$ and online samples $(r=(-0.59), p<0.001)$. The correlation between the Sinhala version of WHO-5 and K10 for the full sample $(r=(-0.56), p<0.001)$ and for both paper-based $(r=(-0.56), p<0.001)$ and online samples $(r=(-0.57), p<0.001)$ were significantly negatively correlated indicating good convergent validity.

There was no difference between the mean WHO-5 scores by sex, ethnicity or religion (Table 3 ). The mean WHO-5 score of those with only a school education was significantly higher than that of those with higher education $\left(t_{265}=2.62, p<0.05\right)$. The mean WHO5 score of students was significantly lower than those employed and unemployed $\left(\mathrm{F}_{2,264}=8.06, p<0.05\right)$.

\section{Factorial validity}

The confirmatory factor analysis partially supported the one factor hypothesis with $\chi_{5}^{2}=22.934(p=0.0003), \frac{\chi^{2}}{d f}=$ 2.09, RMSEA of 0.116 (90\% C.I. $=0.071-0.166)$, a TLI of 0.98, a CFI of 0.99 and a SRMR of 0.03 (Fig. 1). Model fit indices recommended allowing covariances between items 4 and 5 which improved the model significantly; $\chi_{5}^{2}=4.99(p=0.28), \frac{\chi^{2}}{d f}=1.89$, RMSEA of $0.03(90 \%$ C.I. $=$ $0.00-0.10$ ), a TLI of 0.99 , a CFI of 0.99 and a SRMR of 0.02 .

Table 1 Reliability of Sinhala version of WHO-5 well-being index

\begin{tabular}{lllll}
\hline Item & $\begin{array}{l}\text { Corrected item-total } \\
\text { correlation }\end{array}$ & $\begin{array}{l}\text { Squared multiple } \\
\text { correlation }\end{array}$ & $\begin{array}{l}\text { Cronbach's alpha if item } \\
\text { deleted }\end{array}$ & $\begin{array}{l}\text { Factor loadings in } \\
\text { CFA }\end{array}$ \\
\hline I have felt cheerful and in good spirits & 0.707 & 0.541 & 0.814 & 0.843 \\
I have felt calm and relaxed & 0.748 & 0.594 & 0.802 & 0.893 \\
I have felt active and vigorous & 0.635 & 0.427 & 0.832 & 0.725 \\
I woke up feeling fresh and rested & 0.640 & 0.421 & 0.831 & 0.557 \\
$\begin{array}{l}\text { My daily life has been filled with things that } \\
\text { interest me }\end{array}$ & 0.611 & 0.395 & 0.838 & 0.666 \\
\hline
\end{tabular}


Table 2 Intraclass correlation coefficient between initial test and re-test $(n=38)$ for the WHO-5 Sinhala version

\begin{tabular}{llll}
\hline Item & ICC & $95 \%$ Confidence Interval & $\boldsymbol{p}$-value \\
\hline I have felt cheerful and in good spirits & 0.707 & $0.443-0.847$ & $0.521-0.869$ \\
I have felt calm and relaxed & 0.749 & $0.296-0.813$ & $<0.001$ \\
I have felt active and vigorous & 0.638 & 0.002 \\
I woke up feeling fresh and rested & 0.730 & $0.507-0.859$ & $<0.001$ \\
My daily life has been filled with things that interest me & 0.738 & $<.001$ \\
\hline
\end{tabular}

Measurement invariance for gender is presented in Table 4.

Configural invariance for gender groups was established as the $\chi^{2}$ was acceptable $(p>0.05)$ and fit indices of Model 1 were within specified ranges $(\mathrm{CFI}=0.997$; RMSEA $=$ 0.048 (CI: 0.00-0.09)). Next a metric invariance model (Model 2) was tested. This model too had acceptable fit, the $\chi^{2}$ having a $p>0.05$ with fit indices within specified ranges $(\mathrm{CFI}=0.997$; RMSEA $=0.06$ (CI: 0.00-0.095)).

The DIF test $\left(\chi^{2}\right)$ was however significant $(p<0.05)$. As the fit indices $(\Delta \mathrm{CFI}<0.01$ and $\Delta$ RMSEA $<0.015)$ were acceptable, it supported metric invariance. Subsequently, a scalar/threshold invariance model was tested (Model 3) where factor loading and thresholds were constrained to be equal. This model had adequate fit $\left(\chi^{2}\right.$ was $\left.p>0.05\right)$; CFI $=0.994$; RMSEA $=0.05(\mathrm{CI}$ : $0.00-0.085)$. The DIF test $\left(\Delta \chi^{2}\right)$ was not significant $(p>0.05)$, and change in fit indices were acceptable $(\Delta \mathrm{CFI}<0.01$ and $\Delta$ RMSEA $<0.015)$ supporting scalar invariance.

Finally, a strict invariance test (Model 4) was tested. This model had marginal fit $\left(\mathrm{X}^{2}\right.$ was $\left.p<0.05\right)$; but CFI = 0.992; and RMSEA $=0.056$ (CI: $0.10-0.088$ ). The DIF test $\left(\Delta \mathrm{X}^{2}\right)$ was significant $(p<0.05)$, but the change in fit indices were acceptable $(\Delta \mathrm{CFI}<0.01$ and $\Delta$ RMSEA $<$ $0.015)$ providing mixed support for strict invariance.

Invariance tests for occupation, age and method of data collection were not supported as the baseline models were mis-specified [45]. Detailed results can be obtained from the researchers.

\section{Discussion}

This study had its aim to assess psychometric properties of a translated version of the WHO-5 in Sinhala language, the main language used by the majority, in a community sample in Sri Lanka. Following accepted translation, the study provides evidence of good reliability and validity of the scale. We report a Cronbach's alpha of 0.85 for the Sinhala translation which can be considered as very good even though the Persian and Taiwanese translations reported a higher Cronbach's alpha $(\alpha=0.94)$. Other measures of reliability such as test-retest reliability assessed on a sample of 38 and congeneric reliability add to the evidence that the Sinhala translation of WHO-5 is a reliable tool. However, the small sample size used to assess test-retest reliability may have an impact on the ICC at item level.

Factorial validity of the WHO-5 was tested using CFA. The chi-square test result often varies according to the sample size [25]. Both the CFI and TLI showed excellent fit, despite a high RMSEA. Values of RMSEA $>0.05$ have been reported in other validation studies of WHO-5 [12, 13]. Reasons for similar misfit of RMSEA while other fit indices have been satisfactory have been reported in the literature [46].

Table 3 Association between WHO-5 Sinhala version scores and selected variables

\begin{tabular}{|c|c|c|c|}
\hline Sub group & & WHO-5 (mean \pm SD) & p-value \\
\hline \multirow[t]{2}{*}{ Age Category } & age $<=40(n=202)$ & $55.00 \pm 24.3$ & $0.234^{a}$ \\
\hline & age $>40(n=65)$ & $59.08 \pm 22.5$ & \\
\hline \multirow[t]{2}{*}{ Sex } & Male $(n=75)$ & $52.68 \pm 25.0$ & $0.158^{\mathrm{a}}$ \\
\hline & Female $(n=192)$ & $57.28 \pm 23.3$ & \\
\hline \multirow[t]{2}{*}{ Ethnicity } & Sinhala $(n=256)$ & $56.20 \pm 23.9$ & $0.504^{a}$ \\
\hline & Tamil and Moor $(n=11)$ & $51.28 \pm 24.3$ & \\
\hline \multirow[t]{2}{*}{ Religion } & Buddhist $(n=189)$ & $54.24 \pm 24.4$ & $0.059^{\mathrm{a}}$ \\
\hline & Other $(n=78)$ & $60.32 \pm 22.2$ & \\
\hline \multirow[t]{2}{*}{ Educational Status } & School education up to grade $13(n=112)$ & $60.48 \pm 23.5$ & $0.009^{a}$ \\
\hline & Degree and above $(n=155)$ & $52.76 \pm 23.7$ & \\
\hline \multirow[t]{3}{*}{ Employment Status } & Not employed $(n=62)$ & $61.08 \pm 23.1$ & $0.001^{b}$ \\
\hline & Student $(n=84)$ & $47.60 \pm 23.8$ & \\
\hline & Employed $(n=121)$ & $59.20 \pm 23.0$ & \\
\hline
\end{tabular}




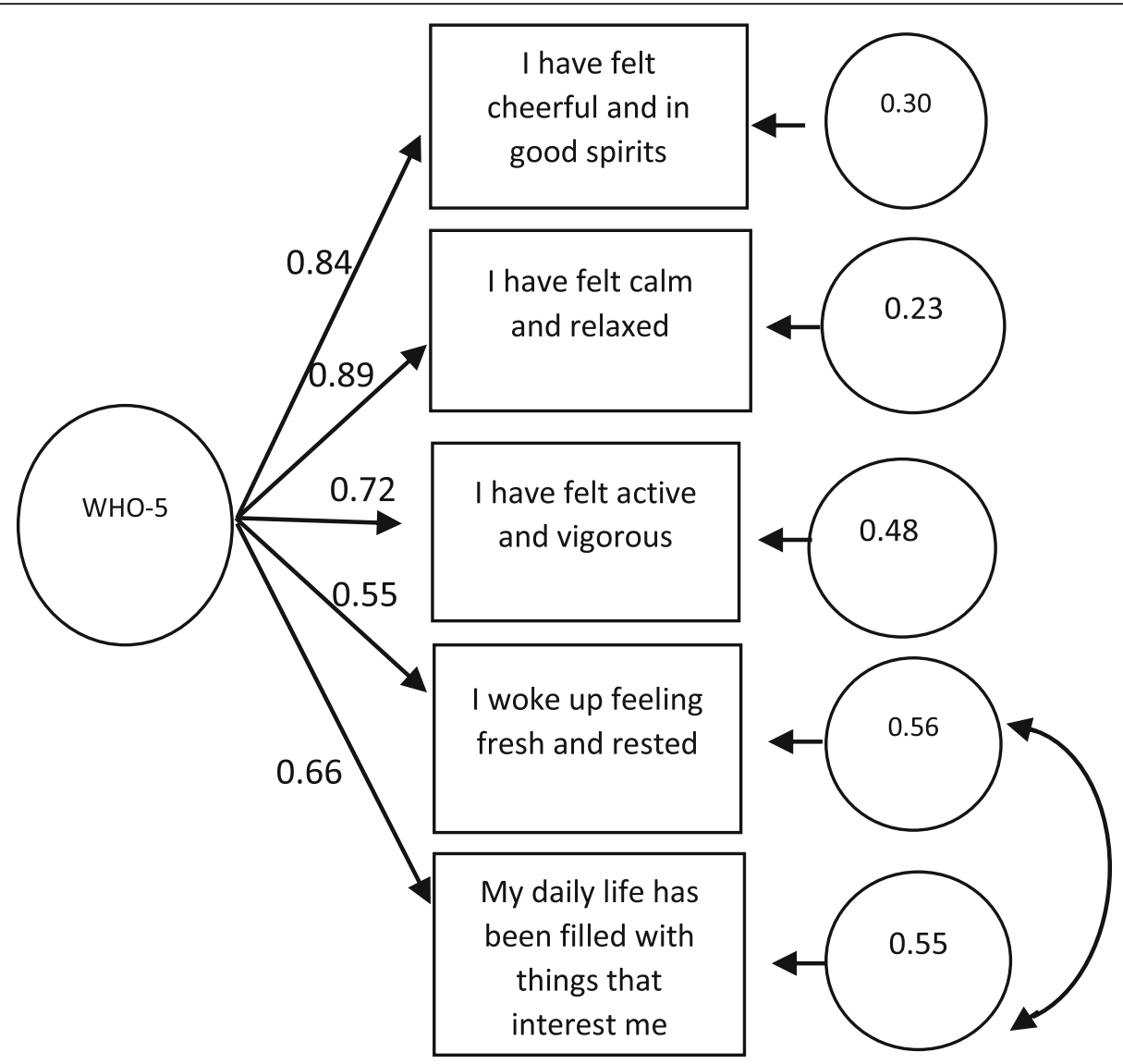

Fig. 1 Path diagram of confirmatory factor analysis of a single factor model

Our study found that the residual variances for items 4 and 5 were borderline at the higher end. When tested in a post-hoc model covarying the two items, a non-significant Chi-square $(p>0.05)$ and better fit indices with RMSEA < 0.05 were obtained. Xia and Yang state that further studies are needed to seek alternative methods for goodness-of-fit evaluation with ordered categorical data [35]. Shi et al. has demonstrated that SRMR is relatively free from the choice of estimation method and the same population cut-offs can be applied regardless of the estimation method employed [34]. In the tested model a SRMR $<0.05$ indicates acceptable model fit. Based on all of these considerations we feel there is sufficient support for factorial validity of the translated WHO-5. However, we recommend that further tests of validity be undertaken in larger and more generalizable samples.

We tested convergent validity of the WHO-5 comparing with two well tested measures of depression and anxiety that had been previously validated in Sri Lanka. In this population, the correlation between WHO-5 and PHQ-9 scores is at the lower end of the range (- 0.39 to $-0.73)$. Such values have also been found in other studies, $[12,13,15,47]$. WHO- 5 scores were negatively correlated with $\mathrm{K} 10$ scores.

The mean WHO-5 score for the Sinhala speaking Sri Lankan population with a mean age of 34 years was $14( \pm$ 5.9). This score is similar to the score of $14.3( \pm 4.4)$ reported in a Thai validation study for a population with a mean age

Table 4 Fit statistics for measurement equivalence/invariance of WHO-5 scores across gender groups

\begin{tabular}{|c|c|c|c|c|c|c|c|c|c|c|c|c|}
\hline \multirow[b]{2}{*}{ Model } & \multirow[b]{2}{*}{$x^{2}$} & \multirow[b]{2}{*}{$d f$} & \multirow[b]{2}{*}{$p$} & \multicolumn{4}{|l|}{$\Delta x^{2}$} & \multirow[b]{2}{*}{$\triangle C F I$} & \multirow[b]{2}{*}{ TLI } & \multirow[b]{2}{*}{ RMSEA } & \multirow[b]{2}{*}{ RAMSEA Cl } & \multirow[b]{2}{*}{$\triangle R M S E A$} \\
\hline & & & & $\Delta x^{2}$ & $\Delta D F$ & $p$ & CFI & & & & & \\
\hline 1.Configural invariance & 27.38 & 21 & 0.15 & - & - & - & 0.997 & - & 0.997 & 0.048 & $0.000-0.093$ & - \\
\hline 2.Metric invariance & 35.35 & 25 & 0.08 & 9.78 & 4 & 0.04 & 0.995 & 0.002 & 0.996 & 0.056 & $0.000-0.095$ & 0.008 \\
\hline 3.Scalar invariance & 45.30 & 34 & 0.09 & 13.00 & 9 & 0.06 & 0.994 & 0.003 & 0.997 & 0.050 & $0.000-0.085$ & 0.002 \\
\hline 4.Strict invariance & 55.24 & 39 & 0.04 & 14.74 & 5 & 0.01 & 0.992 & 0.005 & 0.996 & 0.056 & $0.010-0.088$ & 0.008 \\
\hline
\end{tabular}


of 44 years [48]. We found no significant differences in the mean scores by age, gender, ethnicity or religion. The finding that the mean score was significantly lower in those with a higher level of education was contrary to our hypothesis. This is further explained by the low mean score among students, who were mostly from a University. University students are known to experience higher levels of distress due to academic pressure and burnout [49]. The unemployed group comprised mostly home makers with the majority being females. It has been reported that homemakers are as happy as those who work in salaried jobs [50].

The second aim of the study was to test measurement invariance of the WHO-5 among diverse groups using Sinhala language in Sri Lanka. We tested measurement invariance between groups by gender, age (categorised as $<=40$ and $>40$ ), occupation and method of administration. The results of measurement invariance by gender showed that the five items of the WHO-5 measure well-being in both males and females similarly for within group analyses, mean group comparisons, and selection purposes. The strict invariance test provided ambiguous findings but needs to be interpreted cautiously. There is yet debate about the use of this step in measurement invariance analysis [39]. Some authors have claimed that requiring residual invariance prior to latent mean comparisons is unrealistic and that lack of residual invariance may not meaningfully influence latent mean comparisons $[40,51$, 52]. However, our examination of measurement invariance by age, occupation and method of administration encountered a mis-specified configural model and further testing was not possible [45].

The literature cautions that small samples (various authors give different values) are more prone to error in model fit indices in CFA and MG-CFA [53, 54]. As the groups by age, occupation and method of administration were unequal, minimum sample size may have affected model testing. Future research is required with larger samples to test the various characteristics of WHO-5.

\section{Conclusion}

The Sinhala translation of WHO-5 well-being index has shown acceptable psychometric properties and can be used for assessing mental well-being in the Sinhala speaking community in Sri Lanka. Further testing of the measure with larger and diverse (including different ethnic/cultural) groups are indicated to test measurement invariance.

\section{Supplementary information}

Supplementary information accompanies this paper at https://doi.org/10. 1186/s12955-020-01532-8.

Additional file 1.

Additional file 2.

\section{Abbreviations}

ANOVA: Analysis of variance; AUC: Area Under the Curve; CFA: Confirmatory Factor Analysis; CFI: Comparative Fit Index; DFI: Differential Item Functioning; DSM: Diagnostic and Statistical Manual of Mental Disorders; ICC: Intraclass

Correlation Coefficient; IRT: Item Response Theory; K10: Kessler Psychological Distress Scale; LMIC: Low-and-middle-income countries; MOH: Medical Officer of Health; NLR: Likelihood ration for a negative test; NPV: Negative Predictive Value; PHQ-9: Patient Health Questionnaire; PLR: Likelihood ratio for a positive test; PPV: Positive Predictive Value; RMSEA: Root Mean Square Error of Approximation; ROC: Receiver Operator Characteristics; SCID: Structured Clinical Interview for Diagnostic and Statistical Manual of Mental Disorders; SD: Standard Deviation; SEM: Structural Equation Model; SRMR: Standard Root Mean Square Residual; TLI: Tucker-Lewis Index; WHO-5: World Health Organization well-being index; WLSMV: Variance adjusted weighted least square estimator

\section{Acknowledgements}

The participants of this research and the staff of the department of Public Health, Faculty of Medicine, University of Kelaniya are acknowledged for their support.

\section{Code availability}

Codes will be made available.

\section{Authors' contributions}

BRRP and AC were involved in the design and organization of the study, data collection, data analysis and manuscript writing. RJ and ARW were involved in the design and organization of the study, data analysis and manuscript writing. The authors read and approved the final manuscript.

\section{Funding}

This study did not receive any funding

\section{Availability of data and materials}

The datasets supporting the conclusions of this article are included within the article (and its additional files).

\section{Ethics approval and consent to participate}

Ethics approval was obtained from the Ethics Review Committee of the Faculty of Medicine, University of Kelaniya, Sri Lanka (Ref.No.P/128/06/2019). Informed written consent was obtained from all participants prior to responding to the scale and questionnaire.

\section{Consent for publication}

All participants consented to the data being used for publication purposes without disclosing any personal information. All authors read and approved the final version and have consented for publication.

\section{Competing interests}

All authors have no conflicts of interest to declare.

\section{Author details}

'Department of Public Health, Faculty of Medicine, University of Kelaniya, P.O. Box 6, Thalagolla Road, Ragama 11010, Sri Lanka. ${ }^{2}$ School of Public Health \& Community Medicine, University of New South Wales, Randwick, NSW 2052, Australia.

Received: 4 May 2020 Accepted: 7 August 2020

Published online: 11 September 2020

References

1. Topp CW, Østergaard SD, Søndergaard S, Bech P. The WHO-5 well-being index: a systematic review of the literature. Psychother Psychosom. 2015;84: 167-76.

2. Bech P, Gudex C, Johansen S. The WHO (ten) Weil-being index: validation in diabetes. Psychother Psychosom. 1996;65:183-90.

3. WHO-5 Questionnaires. [cited 2019 Nov 18]. Available from: https://www. psykiatri-regionh.dk/who-5/who-5-questionnaires/Pages/default.aspx.

4. Allgaier A-K, Pietsch K, Frühe B, Prast E, Sigl-Glöckner J, Schulte-Körne G. Depression in pediatric care: is the WHO-five well-being index a valid 
screening instrument for children and adolescents? Gen Hosp Psychiatry. 2012;34:234-41.

5. Awata S, Bech P, Yoshida S, Hirai M, Suzuki S, Yamashita M, et al. Reliability and validity of the Japanese version of the World Health Organization-five well-being index in the context of detecting depression in diabetic patients. Psychiatry Clin Neurosci. 2007:61:112-9.

6. Bonnín CM, Yatham LN, Michalak EE, Martínez-Arán A, Dhanoa T, Torres I, et al. Psychometric properties of the well-being index (WHO-5) spanish version in a sample of euthymic patients with bipolar disorder. J Affect Disord. 2018;228:153-9.

7. Bonsignore $M$, Barkow $K$, Jessen $F$, Heun R. Validity of the five-item WHO well-being index (WHO-5) in an elderly population. Eur Arch Psychiatry Clin Neurosci. 2001;251(Suppl 2):I127-31.

8. Christensen $\mathrm{KS}$, Haugen W, Sirpal MK, Haavet OR. Diagnosis of depressed young people--criterion validity of WHO-5 and HSCL-6 in Denmark and Norway. Fam Pract. 2015;32:359-63.

9. de Souza CM, Hidalgo MPL. World Health Organization 5-item well-being index: validation of the Brazilian Portuguese version. Eur Arch Psychiatry Clin Neurosci. 2012;262:239-44.

10. de Wit M, Pouwer F, Gemke RJBJ, Delemarre-van de Waal HA, Snoek FJ. Validation of the WHO- 5 well-being index in adolescents with type 1 diabetes. Diabetes Care. 2007;30:2003-6.

11. Furuya M, Hayashino Y, Tsujii S, Ishii H, Fukuhara S. Comparative validity of the WHO-5 well-being index and two-question instrument for screening depressive symptoms in patients with type 2 diabetes. Acta Diabetol. 2013; 50:117-21.

12. Hajos TRS, Pouwer F, Skovlund SE, Den Oudsten BL, Geelhoed-Duijvestijn PHLM, Tack CJ, et al. Psychometric and screening properties of the WHO-5 well-being index in adult outpatients with type 1 or type 2 diabetes mellitus. Diabet Med. 2013;30:e63-9.

13. Halliday JA, Hendrieckx C, Busija L, Browne JL, Nefs G, Pouwer F, et al. Validation of the WHO-5 as a first-step screening instrument for depression in adults with diabetes: results from diabetes MILES - Australia. Diabetes Res Clin Pract. 2017;132:27-35.

14. Lucas-Carrasco R. Reliability and validity of the Spanish version of the World Health Organization-five well-being index in elderly: validity of the Spanish WHO-5 in elderly. Psychiatry Clin Neurosci. 2012;66:508-13.

15. Dadfar M, Momeni Safarabad N, Asgharnejad Farid AA, Nemati Shirzy M, Ghazie pour Abarghouie F. Reliability, validity, and factorial structure of the World Health Organization-5 well-being index (WHO-5) in Iranian psychiatric outpatients. Trends Psychiatry Psychother. 2018:40:79-84.

16. Abdulameer SA, Al-Jewari WM, Sahib MN. Psychological health status and salivary IgA among pharmacy students in Iraq: validation of PSS-4 and WHO-5 well-being (Arabic version). Pharm Educ. 2019;19:10-8.

17. Barua A, Kar N. Screening for depression in elderly Indian population. Indian J Psychiatry. 2010;52:150.

18. Guð̋mundsdótttir HB, Ólason DP, Guð̌mundsdóttir DG, Sigurð̌sson JF. A psychometric evaluation of the Icelandic version of the WHO-5. Scand J Psychol. 2014;55:567-72.

19. Sischka P. The WHO-5 Well-Being Index - Testing measurement invariance across 33 countries. In: Soc Behav Sci Psychol Soc Ind Organ Psychol. Germany; 2018. Available from: http://hdl.handle.net/10993/38786.

20. WHO | Process of translation and adaptation of instruments. [cited 2020 Feb 27]. Available from: https://www.who.int/substance_abuse/research_tools/ translation/en/.

21. Tsang S, Royse C, Terkawi A. Guidelines for developing, translating, and validating a questionnaire in perioperative and pain medicine. Saudi J Anaesth. 2017;11:80

22. Knafl K, Deatrick J, Gallo A, Holcombe G, Bakitas M, Dixon J, et al. The analysis and interpretation of cognitive interviews for instrument development. Res Nurs Health. 2007;30:224-34.

23. Kroenke K, Spitzer RL, Williams JBW. The PHQ-9: validity of a brief depression severity measure. J Gen Intern Med. 2001;16:606-13.

24. Yiengprugsawan V, Kelly M, Tawatsupa B. Kessler Psychological Distress Scale. In: Michalos AC, editor. Encycl Qual Life Well- Res. Dordrecht: Springer Netherlands; 2014. p. 3469-70. [cited 2019 Nov 8] Available from: http://link. springer.com/10.1007/978-94-007-0753-5_3663.

25. Kline RB. Principles and practice of structural equation modeling. 4th ed. New York: The Guilford Press; 2016.

26. Cohen J. Statistical power analysis for the behavioral sciences. 2nd ed. Hillsdale, N.J: L. Erlbaum Associates; 1988.
27. Koo TK, Li MY. A guideline of selecting and reporting Intraclass correlation coefficients for reliability research. J Chiropr Med. 2016;15:155-63.

28. Schober P, Boer C, Schwarte LA. Correlation coefficients: appropriate use and interpretation. Anesth Analg. 2018:126:1763-8.

29. Diener E. Subjective Well-Being. Psychol Bull. 1984;95:542-75.

30. Finney SJ, Di Stefano C. Non-normal and Categorical data in structural equation modeling. In: Quant Methods Educ Behav Sci. 2nd ed. Charlotte: Information Age Publishing; 2013. p. 439-92.

31. Byrne BM. Structural equation modeling with EQS: basic concepts, applications, and programming. 2nd ed. Mahwah, N.J: Lawrence Erlbaum Associates; 2006.

32. Marsh HW, Hau K-T, Wen Z. In search of Golden rules: comment on hypothesis-testing approaches to setting cutoff values for fit indexes and dangers in overgeneralizing Hu and Bentler's (1999) findings. Struct Equ Model Multidiscip J. 2004:11:320-41.

33. Hu L, Bentler PM. Cutoff criteria for fit indexes in covariance structure analysis: conventional criteria versus new alternatives. Struct Equ Model Multidiscip J. 1999;6:1-55.

34. Shi D, Lee T, Maydeu-Olivares A. Understanding the model size effect on SEM fit indices. Educ Psychol Meas. 2019;79:310-34.

35. Xia Y, Yang Y. RMSEA, CFI, and TLI in structural equation modeling with ordered categorical data: the story they tell depends on the estimation methods. Behav Res Methods. 2019;51:409-28.

36. Maydeu-Olivares A, Shi D, Rosseel Y. Assessing fit in structural equation models: a Monte-Carlo evaluation of RMSEA versus SRMR confidence intervals and tests of close fit. Struct Equ Model Multidiscip J. 2018;25:389402.

37. Shi D, Maydeu-Olivares A. The effect of estimation methods on SEM fit indices. Educ Psychol Meas. 2020;80:421-45.

38. Reynolds CR, Ramsay MC. Bias in Psychological Assessment: An Empirical Review and Recommendations. In: Weiner IB, editor. Handb Psychol. Hoboken: Wiley; 2003. wei1004. [cited 2020 Jul 11] Available from: https:// doi.org/10.1002/0471264385.wei1004.

39. Pendergast LL, von der Embse N, Kilgus SP, Eklund KR. Measurement equivalence: a non-technical primer on categorical multi-group confirmatory factor analysis in school psychology. J Sch Psychol. 2017;60: 65-82.

40. Chen FF. What happens if we compare chopsticks with forks? The impact of making inappropriate comparisons in cross-cultural research. J Pers Soc Psychol. 2008;95:1005-18.

41. Koh KH, Zumbo BD. Multi-group confirmatory factor analysis for testing measurement invariance in mixed item format data. J Mod Appl Stat Methods. 2008;7:471-7.

42. Kim ES, Yoon M. Testing measurement invariance: a comparison of multiple-group categorical CFA and IRT. Struct Equ Model Multidiscip J. 2011;18:212-28.

43. Dimitrov DM. Testing for factorial invariance in the context of construct validation. Meas Eval Couns Dev. 2010;43:121-49.

44. Epskamp S. semPlot: Unified Visualizations of Structural Equation Models. Struct Equ Model Multidiscip J. 2015;22:474-83.

45. Yuan K-H, Bentler PM. On Chi-Square difference and $z$ tests in mean and covariance structure analysis when the base model is Misspecified. Educ Psychol Meas. 2004:64:737-57.

46. Browne MW, MacCallum RC, Kim C-T, Andersen BL, Glaser R. When fit indices and residuals are incompatible. Psychol Methods. 2002;7:403-21.

47. Lowe B. Comparative validity of three screening questionnaires for DSM-IV depressive disorders and physicians? Diagnoses. J Affect Disord. 2004;78: $131-40$.

48. Saipanish $R$, Lotrakul $M$, Sumrithe $S$. Reliability and validity of the Thai version of the WHO-five well-being index in primary care patients: reliability and validity of Thai WHO-5. Psychiatry Clin Neurosci. 2009;63:141-6.

49. Wimberly CE. Mental well-being in students at university of Ruhuna faculty of medicine: a cross-sectional study. Duke University: Master's Thesis; 2019. Available from: https://hdl.handle.net/10161/18887.

50. Wright JD. Are working women really more satisfied? Evidence from Several National Surveys. J Marriage Famh. 1978:40:301.

51. Brown TA. Confirmatory factor analysis for applied research. Second edition. New York. London: The Guilford Press; 2015.

52. Xing C, Hall JA. Confirmatory factor analysis and measurement invariance testing with ordinal data: an application in revising the flirting styles inventory. Commun Methods Meas. 2015;9:123-51. 
53. Chen FF. Sensitivity of goodness of fit indexes to lack of measurement invariance. Struct Equ Model Multidiscip J. 2007;14:464-504.

54. Gonzalez-Roma V, Hernandez A, Gomez-Benito J. Power and type I error of the mean and covariance structure analysis model for detecting differential item functioning in graded response items. Multivar Behav Res. 2006:41:29-53.

\section{Publisher's Note}

Springer Nature remains neutral with regard to jurisdictional claims in published maps and institutional affiliations.

Ready to submit your research? Choose BMC and benefit from:

- fast, convenient online submission

- thorough peer review by experienced researchers in your field

- rapid publication on acceptance

- support for research data, including large and complex data types

- gold Open Access which fosters wider collaboration and increased citations

- maximum visibility for your research: over $100 \mathrm{M}$ website views per year

At $B M C$, research is always in progress.

Learn more biomedcentral.com/submissions 